\title{
COORDENAÇÃO PEDAGÓgICA E SUAS ATRIBUIÇÕES PARA A PRÁTICA DOCENTE NA COMUNIDADE RIBEIRINHA MUTUACÁ DE BAIXO CAMETÁ, NO ANO DE 2020.
}

CLAURIETE PINTO BATISTA

\section{RESUMO}

A investigação teve a objetividade de analisar o papel da coordenação pedagógica e suas atribuições para a prática docente na comunidade ribeirinha Mutuacá no município de Cametá, no ano de 2019. A pesquisa fez uso do estudo misto com desenho DITRAS, tendo o enfoque misto direcionado pelo alcance exploratório analítico. Cabe investigar se a atuação da coordenação pedagógica tem suas atribuições de maneira positiva para a prática docente contribuindo positivamente na aquisição da qualidade do processo ensino aprendizagem do discente porem muitos ainda são os desafios e dificuldades vivenciadas por esse profissional no ambiente educativo. Seja por ausencia de formações, de autonomia dos coordenadores, dos professores e ausencia de recursos que auxilie sua pratica no ambiente escolar.

Palavras-chave: Coordenação pedagógica. Prática docente. Ensino aprendizagem

\begin{abstract}
The research had the objectivity to analyze the role of pedagogical coordination and its attributions for teaching practice in the Mutuacá riverside community in the municipality of Cametá, in 2019. The research used the mixed study with DITRAS design, with the mixed focus directed by the analytical exploratory scope. It is worth investigating whether the performance of pedagogical coordination has its attributions in a positive way for the teaching practice contributing positively to the acquisition of the quality of the teaching process learning the student but many are still the challenges and difficulties experienced by this professional in the educational environment. Whether by absence of training, autonomy of coordinators, teachers and absence of resources that help their practice in the school environment.
\end{abstract}

Keywords: Pedagogical coordination. Teaching practice. Teaching learning 


\section{INTRODUÇÃO}

A prática docente para funcionar em termo de promover a qualidade no ambiente de formação do discente necessita ser acompanhada e assistida por profissionais que junto com o educador buscam solucionar as problemáticas e os conflitos e dificuldades encontradas no processo de formação do aluno. A pesquisa tem como temática analisar "o papel da coordenação pedagógica e suas atribuições para a prática docente na comunidade ribeirinha Mutuacá de Baixo no município de Cametá, no ano de 2019”. Pois a relação entre coordenação técnica e docencia nas escolas pública brasileiras sempre foram relçaões conflituosas, se observa uma disputa desnecessária no desempenho das funções, no espaço escolar, em que muitas vezes a função do coordenador ou do técnico no espçao escolar acaba sendo distorcida.

Coordenadores técnicos pedagógicos não conceguem trabalhar de forma amigável com o educador, há uma ação conflituosa que acaba prejudicando o trabalho docente. O educador muitas vezes sente-se precionado pelas cobranças em termo da qualidade de seu trabalho, mais noentanto esses reclamam que não recebem apoio necessário para sanar as dificuldades apresentadas em sala de aula. A coordenação pedagógica nao está para estabelecer um processo de ordem com o corpo docente, mais sim de suporte de acolhida tanto do professor como do aluno. A fim de promover a diminuição dos problemas em sala de aula.

A pesquisa ocorreu no campo da educação, destaca-se a contextualização da investigação o município de Cametá, este localiza-se, na mesorregião nordeste paraense, em uma área de $3.081,367 \mathrm{~km}^{2}$. A palavra "Cametá" vem do Tupi “caá” (degrau, palanque, elevação) e Mutá (floresta, mato, vegetação densa) logo Cametá numa tradução livre significa "degrau da floresta". A fundação do município data 24 de dezembro de 1635. Limitada, ao

norte pela cidade de limoeiro do Ajuru, ao sul, por Mocajuba, a leste, por Igarapé-Miri e a oeste, por Oeiras do Pará. O município Cametaense apresenta uma população de 134.100 habitantes.

Este estudo teve a interrogante central que direcionou a investigação "Quais os desafios da coordenação pedagógica e suas atribuições para a prática docente na comunidade ribeirinha Mutuacá de Baixo no município de Cametá, no ano de 2019”? Essa indagação surgiu a partir de alguns olhares atentos sobre a realidade da escola e a relação entre a função do educador e do coordenador pedagógico e o andamento da qualidade do processo e ensino aprendizagem. 
Sabe-se, pois que é fundamental para o aperfeiçoamento das práticas educativas dos educadores, a busca de novos conhecimentos e a escola, através do trabalho desempenhado pelo coordenador pedagógico, pode favorecer ricamente está prática, desde que, este profissional, esteja também munido dos conhecimentos necessários que possam favorecer uma boa formação aos docentes. Se o coordenador colocar em prática as ações educativas, proporcionará, aos educadores um contato mais eficiente e eficaz, na compreensão da significância do trabalho dos conteúdos metodológico para o aluno.

A relação do coordenador com o docente precisa ser amigável e respeitosa em que através do trabalho participativo estes promovam os aspectos imprescindíveis da educação básica da escola, quanto o desenvolvimento e a aprendizagem das crianças.

O coordenador tem a função de contribuir com o processo de ensino-aprendizagem das crianças propondo ao professor enriquecer sua prática pedagógica, onde devem evidencia ações conjuntas que auxiliem o educador nas dificuldades encontradas em sala de aula, portanto o coordenador contribuirá com a prática docente, orientando, auxiliando, a ação do fazer docente, sendo um suporte para que as dificuldades apresentadas pelos discentes sejam sanadas de maneira positiva. Portanto, coordenador e docente precisam trabalhar em uma postura crítica, reflexiva e dialógica promovendo ações que estimulem o crescimento profissional e a aprendizagem para a comunidade escolar.

O papel da coordenação pedagógica necessita ocorrer na interação das atribuições para a prática docente, onde contribua com o educador para que o processo de planejar, organizar, avaliar e reorientar as atividades educativas sejam ações compartilhadas favorecendo um ensino que atenda às necessidades dos professores, alunos, e de todos os envolvidos no processo educacional.

A qualidade educacional advém de um trabalho árduo, somando esforços dos coordenadores, professores e alunos, através de uma ação educativa pautada no diálogo, na ação crítica e reflexiva, onde as vivencias e experiências dos alunos sejam valorizadas, ou seja, a escola necessita trabalhar em parceria com a comunidade onde ela está inserida.

Vale ressaltar que promover um ensino de qualidade não é um desafio fácil, todos os seguimentos educacionais precisam assumir seu papel, contribuindo para que as dificuldades educacionais sejam sanadas ou amenizadas.

A ação do educador e do coordenador não pode ser direcionada sobre olhares conflituosos ou como um espaço de disputa e poder, mais sim na oportunidade de criar ações que tornem a função do educador e do coordenador uma relação de respeito, harmoniosa, em 
que ambos trabalhem de forma coletiva participativa buscando resultados eficientes nas ações de ensino que forme de fato um aluno cidadão.

A ação do coordenador e do docente quando ocorre de maneira complementar, as mudanças passam a ser positivas sejam nas ações metodológicas, avaliativas, na própria didática. Ou seja, o coordenador, assume a responsabilidade de orientar, auxiliar, acompanhar, conduzir o trabalho do educador, em que juntos através de uma postura dialógica, flexível, trocaram experiências e ideias para promover a melhoria do ensino.

A pesquisa justifica-se no campo da educação, pois o grande desafio de todas unidades de ensino sejam elas públicas ou particulares, almejam desenvolver um ensino de qualidade, e o termo qualidade não pode ser centrado na ação do docente, a prática pedagógica é apenas um elemento que compõe a conjuntura educacional para promover a tão sonhada qualidade no processo formativo do discente.

Portanto, organizar o espaço de ensino-aprendizagem, promover condições para que o educador desenvolva as atividades pedagógicas com eficiência, investir em recursos, didáticos pedagógicos, adaptar estruturas, inserir as famílias nas ações escolares, elaborar projetos e ações que promovam aos alunos aulas inovadoras e atrativas, depende da ação coletiva de todos em que o trabalho participativo seja um elemento diário no ambiente escolar.

Portanto gestor, coordenador, supervisor, e demais profissionais da educação precisam atuar de forma cooperativa para contribuir com o trabalho do docente oportunizando a ele orientação de sua pratica, auxiliando nas dificuldades de sala de aula, assim a gestão escolar necessita realizar um trabalho de parceria e integração entre os profissionais da educação.

A escola está inserida em um meio social que precisa ser compreendido pelos profissionais da educação, professores coordenadores gestores precisam trabalhar em conjunto para promover um ensino de qualidade. A aproximação com o aluno, conhecer sua realidade valorizar suas vivencias e experiências é necessário no âmbito escolar, assim professor coordenador e gestor, ao criar uma relação de confiança, passa a conhecer os alunos, suas dificuldades, suas necessidades e investir nas potencialidades dos mesmos, é notório a influência do meio social no processo de aprendizagem do aluno.

A construção de uma escola de qualidade não depende do docente, mais da união de forças de todos os profissionais da educação. A escola de maneira participativa e colaborativa necessita promover ações, e projetos que prime por uma educação que forme cidadãos que reconheça seus direitos e deveres capazes de transformar seu meio.

Compreender a função do coordenador e do professor no espaço escolar torna-se uma ação necessária, para que as metas, ações e projetos traçados possam ser executados visando 
resultados com eficiência. O coordenador desenvolve suas ações escolares sempre trabalhando de forma atuante com o professor, assim ele estará sempre perto do aluno e do docente acompanhando o processo de ensino aprendizagem mediado pela aplicação da pratica de ensino. O coordenador precisa acompanhar as metodologias aplicadas em sala de aula, atuando junto ao professor para que as dificuldades apresentadas no processo de ensino sejam sanadas diante de novas estratégias e métodos, assim através de um trabalho cooperativo professor e coordenador trocam experiências, afim de, elaborar novas ações e proposta para sanar as dificuldades encontradas em sala de aula.

\section{COORDENAÇÃO PEDAGÓGICA E SUA FUNÇÃO NO ESPÇAO ESCOLAR}

A função do coordenador pedagógico é a de incorporar no espaço escolar novas práticas essenciais dentro do campo da educação auxiliando e orientando o trabalho do professor a atuação do coordenador ocorrer em diferentes áreas no espaço escolar acompanhando o processo de ensino-aprendizagem, a relação professor aluno, professor família, mediando conflitos e auxiliando as dificuldades encontradas pelo educador em sala de aula.

O coordenador deverá atuar junto com os professores, auxiliando e contribuindo para que o trabalho docente tenha bons resultados. O coordenador precisa atuar com teorização, mais também com praticidade, ou seja, não basta só encher o professor de informações teóricas, mais sim vivenciar a pratica no dia a dia, ser parte do processo de ensino, o coordenador deve interagir no cotidiano escolar, observando, ouvindo, orientando, auxiliando, professores, aluno e até mesmo as famílias, criando uma relação afetiva e respeitosa entre os sujeitos escolares.

O coordenador é responsável pelas dimensões de coordenação pedagógica e orientação educacional. Deve prestar assistência na área pedagógica e didática aos docentes da sua instituição. Pode ainda acompanhar a interação entre pais, alunos e professores e intervir nesse contexto, além de promover, por meio do conselho de classe, ações referentes a dificuldades apresentadas por alunos e professores, preocupando-se com a qualidade do que é ensinado aos alunos e com o desempenho escolar deles. (GROCHOSKA, 2014, p.55),

O coordenador, assim como, o professor necessita estar sempre em formação, pois a sociedade muda diariamente isso também torna o processo educativo dinâmico, e flexível a escola não pode ser compreendida como um ambiente estático, mórbido, tendo sua proposta de ensino pronta e acabada. A escola é um ambiente de evolução transformação, flexível de diferentes discursos e debates, em que a criticidade precisa ser uma ação diária promovendo a 
construção de um educar que direcione o pensamento crítico do aluno constituindo a ação cidadã para que o aluno seja formado com base nos valores, nos preceitos éticos, profissionais, sociais, culturais, sendo este conhecedor de seus direitos e deveres.

O coordenador deve aturar em parceria com o professor atendendo suas necessidades frente as dificuldades enfrentadas no dia a dia escolar, mediando as relações conflituosas, seja com a família ou com os alunos, sabendo ouvir, dialogar, intervir e tomar decisões que promovam o processo de ensino aprendizagem de forma eficaz. $\mathrm{O}$ coordenador precisa reconhecer sua atuação no espaço escolar, construindo uma relação amistosa e harmoniosa com os demais profissionais. Portanto tanto o educador como o coordenador necessita está em constante formação, buscar novos conhecimentos e estratégias para aquisição de novas ações educativas.

Pimenta (1997) argumenta que "o professor utiliza o conhecimento adquirido no processo de ensino, e que não se resume na informação obtida, mas sim no poder de trabalhar com esta informação, processá-la, classificá-la, analisá-la e contextualizála".

O papel da coordenação perpassa em apresentar ao educador estratégias de ensino para ministra os conteúdos, tem o dever de orientar, auxiliar, informar, mediar ações que sejam somativa para o desenvolvimento de um bom trabalho do professor. Adriano (2017, p. 107) afirma que "O coordenador pedagógico, na definição de sua função, enfrenta alguns desafios para construir sua identidade profissional. Mesmo assim, necessita buscar sua identidade de atuação que transcende somente o trabalho na dimensão pedagógica. "

A ação da coordenação assumi além da função pedagógica a ação social, institucional, até mesmo emocional, já que cabe a ele orientar, mediar não só a ação do trabalho docente, mais os desafios que ocorrem em sala de aula, como problemas com as famílias, conflitos emocionais, atos violentos, entre os alunos.

Entretanto as exigências do coordenador pedagógico para práticas de ensino da sala de aula requerem algumas orientações sobre a atividade que procede com consciência dos professores no caminho para promover as metas traçadas para promover o ensino. Para isso, a atuação do coordenador perpassar por um caminho da vida diária, do professor e do aluno, sobre as influencias no aspecto de aprendizagem que causam mudança no processo educativo do aluno.

Muitos são os problemas no campo educacional e entre eles os que mais preocupam estão ligados à evasão, a reprovação, o fracasso escolar e os baixos índices de qualidade educacional. A luta dos profissionais da educação se estende sobre essas principais deficiências que automaticamente estão ligadas a outros fatores que influenciam diretamente 
essa existência. Cita-se as péssimas condições estruturais com salas de aulas quentes, sem ventilação e péssima iluminação, assim como o espaço que acaba sendo limitado pelo excesso de aluno na sala de aula causando a superlotação que inviabiliza o docente ministra uma aula de qualidade.

O coordenador tem função primordial no espaço educativo onde passa a mediar, orientar, acompanhar o trabalho do docente e a relação de aprendizagem do aluno, assim como contribui no auxílio do planejamento, das realizações metodológicas e avaliativas somando esforços para que a educação ocorra com eficiência e qualidade. Assim, a função da coordenação;

Têm uma função mediadora, no sentido de revelar/desvelar os significados das propostas curriculares, para que os professores elaborem seus próprios sentidos, deixando de conjugar o verbo cumprir obrigações curriculares e passando a conjugar os verbos aceitar, trabalhar, operacionalizar determinadas propostas (ALMEIDA E PLACCO, 2011, P 34).

A ação do coordenador precisa ser de parceria com a família integrada com o fazer docente já que a formação discente perpassa pelos aspectos de desenvolvimento físico, intelectual, moral, cultural, social emocional psicológico, além do cognitivo. Daí a necessidade do professor ter apoio do um profissional especializado como o coordenador pra auxiliar, orientar, acompanhar sua prática docente.

No processo escolar professor e coordenador devem trabalhar juntos, partilhando experiências, buscando ações, realizar projetos e atividades que contribuam de maneira positiva no processo de ensino-aprendizagem do aluno. Assim a coordenação deve promover a mediação. Sendo um profissional mediador, orientador, e transformador no ambiente educativo. A dialogicidade, as ações críticas e reflexivas devem ser conduzidas por esse profissional, sendo ele um articulador de ações que promova soluções as problemáticas que ocorrer no dia a dia do ambiente escolar.

No âmbito escolar muitos problemas ocorrem por que muitos profissionais acabam não reconhecendo sua própria função, e assumem outras atividades no ambiente escolar que não é de sua responsabilidade.

$\mathrm{Na}$ escola cada um precisa compreender muito bem seu papel, sua autonomia, sua responsabilidade e compromisso com o processo de ensino do aluno.

O coordenador pedagógico precisa estar integrado com todas as atividades de âmbito pedagógico e sua principal atuação precisa está voltada ao atendimento das necessidades pedagógicas dos docentes. 
Assim o educador estará amparado por um profissional que o ajudará a superar suas dificuldades, contribuirá na orientação de seu planejamento de sua escolha didática, auxiliará nas atividades práticas de sala de aula, assim como irá mediar os conflitos existente com aluno, família buscando de maneira harmoniosa, respeitosa solucionar os problemas em torno do processo de ensino aprendizagem do aluno e do processo de atuação do educador.

O professor em contato com o coordenador tem auxilio ao ministrar os conteúdos, tirar conclusões, associa suas ideias, troca experiência, buscando melhorias no processo de ensino e aprendizagem do aluno.

O mais importante está em entender que o coordenador realmente apresenta uma contribuição positiva ao docente se este estiver na postura de mediador, atuando de forma participativa com o docente e demais profissionais da educação.

Nesse sentido, se tem observado que a relação harmoniosa e respeitosa entre a função do educador e do professor ao ser desempenhando um trabalho de forma correta, em que ambos reconheçam sua função, utilizando no espaço escolar o processo de reflexão e ação sobre a realidade do aluno, construindo assim um novo olhar para a mudança na educação, com certeza neste contexto a educação ganha eficiência e o processo formativo do discente acontece com maior eficiência.

\subsection{Coordenação e docência um campo conflituoso}

Para aborda conceito da coordenação pedagógica e docência num campo conflituoso, a orientação é bem especifica por ser o processo de ensino aprendizagem um processo dinâmico, e complexo, que envolve sujeitos que se relacionam de maneira diferente com pensamentos diferentes. As divergências são muitas, promover um ensino de qualidade perpassa por rupturas de barreiras tradicionais que estão enraizadas nas práticas docentes e até mesmo na própria maneira como a instituição de ensino está organizada.

Os conflitos são de ordens diversas, perpassam pelas relações existentes e interesses de cada profissional que atua no espaço escolar. Por muito tempo os conflitos sobre duas áreas profissionais foram evidenciados no campo educativo entre a coordenação pedagógica e à docência, estes profissionais muitas vezes mantiverem o âmbito escolar como espaço de disputa e poder, criando uma relação conflituosa e muitas vezes turbulenta no ambiente educacional.

Romper com essa ação conflituosa se faz urgente e necessário a escola não pode e não deve ser visto como espaço de disputa ou de conflito entre a atuação da coordenação e da docência, na verdade esses profissionais precisam compreender que suas profissões se 
complementam elas estão interligadas, assim coordenação e docência precisam atuar em parceria, de forma harmoniosa, respeitosa, trocando experiências e promovendo um trabalho de parceria que respeite a autonomia de cada função.

O campo da educação amplia e conceitua a atividade escolar em caráter participativo que é a buscar na disputa de temas sócias e que trata falar de um ensino que tem parte central na realidade sociável em que professor e coordenador aplicam as funções buscando superar as dificuldades e os desafios que enfrentam na escola. Vale lembrar que as realidades da sociedade, da cultura da comunidade local, estão diretamente ligadas a realidade educacional, portanto escola e comunidade necessita estar integradas atuando em conjunto em prol de uma educação de qualidade compromissada com a cidadania.

O docente precisa agir com flexibilidade em aceitar ou concordar com algumas ideias expostas por seu coordenador, pois, é este profissional que o auxiliará nas dificuldades de sua prática e nos desafios de sala de aula, contribuindo positivamente para que o processo formativo do aluno ocorra de forma eficaz.

Na concepção de Pimenta (1997), os saberes docentes podem ser vistos sob três óticas, a da experiência, do conhecimento e dos saberem pedagógicos. No que diz respeito aos saberes da experiência, são aqueles que o professor em formação traz consigo, relativo à sua experiência e vivências como aluno e em atividades docentes. Além disso, os saberes da experiência envolvem aqueles produzidos no cotidiano docente e, nos processos de reflexão da sua própria prática e de colegas de trabalho.

Ao se tratar desse conflito entre esses profissionais que atua na educação tem de se programar um caminho novo na vida desses profissionais, promovendo a boa relação, de convivência, de respeito, de compromisso ainda criar espaço de autonomia para que ambos possam atuar com respeito, compromisso e seriedade. As trocas de experiências são fundamentais nesse processo, pois assim o educador não se sentirá só ou desamparado em meios às dificuldades de sala de aula.

O aspecto do conhecimento da ao educador e ao coordenador a aquisição da teorização não se produz o ensino aprendizagem somente pelo campo da troca de experiências ou da vivencia da pratica, se faz necessário esses profissionais se colocarem na postura de aprendentes, de pesquisadores estarem sempre em buscam de novas estratégias, novos métodos, novos recursos para auxiliar seu fazer educativo.

A formação a capacitação necessita ser uma ação constante, pois as mudanças no campo tecnológico, no campo social, impõem também que haja mudanças sobre a prática docente e a maneira de organização do ensino. 
Os métodos são decididos pela relação de conteúdo, e referem-se aos bens para chegar aos objetivos traçados para transmitir conhecimento, ou seja, ao aproxima do processo de ensino, se faz necessário reunir todas as ações a serem colocada em prática pelo coordenador e professor e repassar pelos educandos para atingir os resultados. Promovendo ainda um processo de ação-reflexão-ação como bem afirmou FREIRE (1996), o ato de avaliar leva a um novo planejar, um (re)organizar e propor novas possibilidades para alcançar determinado resultado.

O terceiro aspecto é a dos saberes pedagógicos, "não bastando apenas experiência e conhecimentos específicos, é preciso também saber ensinar, e isso o professor adquire, constrói e aprimora ao longo de sua formação docente com seu próprio fazer" (PIMENTA, 1997).

Daí a necessidade da construção da práxis em que teoria e pratica se associam promovendo uma fazer docente com muito mais eficiência busca pelo conhecimento pedagógico se dá no envolvimento com o aluno, onde o professor reconhece este e sua identidade, valorizando sua cultura, suas vivencias e experiências.

Os saberes pedagógicos são constituídos pelo docente na compreensão de que a escola é um espaço heterogêneo, multicultural de diversos saberes, cada aluno tem seu tempo de aprender, tem sua história de vida, suas raízes. E valorizar esse saber em sala de aula na prática do educador é uma ação de extrema importância, pois promover um ensino contextualizando fará com que o aluno se reconheça no processo de ensino aprendizagem, tornando-se agente construtor de seu próprio conhecimento.

A aprendizagem acontecer sob a ação de infinitos fatores, portanto o espaço de sala de aula é só mais um espaço de atividades pedagógicas o educador pode e deve explorar não só os ambientes escolares mais também a própria comunidade.

A aprendizagem é um processo de mudança continua que está sempre em transformação seja na vida educativa seja na vida em sociedade.

O professor passa a ser o espelho do aluno e também da sociedade, do educador e do coordenador assim como dos demais profissionais da educação são cobradas posturas éticas, morais na comunidade escolar. Assim todos os sujeitos precisam ser respeitados e agir com respeito, sabendo que cada pessoa tem sentimentos, valores, espontaneidade, autonomia, etc. Ao conduzir e incentivar o processo de ensino em atribuição da aprendizagem dos alunos tornar útil um conjunto de ações, projetos, planos, metas e procedimentos a que somados promovem a qualidade do ensino e uma formação do aluno com maior eficiência. 
As inovações metodológicas, o novo em sala de aula causa medo e desconforto ao professor que muitas vezes se sente perdido com tantas mudanças que ocorrem tão rapidamente no ambiente escolar.

As mudanças causam incomodo sair da zona de conforto promove um grau de incerteza se as novas experiências, novas orientações de ensino darão certo, se o educador conseguirá trabalhar de forma diferenciada do que já estava acostumado. O coordenador acaba sendo visto como um profissional que quer mudar o jeito do educador ensinar. e na verdade ele tem o papel de mediar esses conflitos, amenizar as dificuldades de sala de aula enfrentado pelo professor no processo de ensino.

Assim acredita-se em um trabalho participativo, coletivo, harmonioso e respeitoso que promova a troca de experiência entre coordenação e docência.

A atuação da coordenação pedagógica no ambiente escolar está em atender os aspectos pedagógicos auxiliando, orientando e mediando o processo educacional, mais também atende aspectos de ordem burocráticas, disciplinar e organizacional, portanto a ação do coordenador está em acompanhar não só o trabalho do professor mais de todo processo que ocorre em termo da formação do aluno. Assim compete a coordenação pedagógica; assumir três posturas no espaço educacional: articulador, formador e transformador para favorecer uma educação que tenha a qualidade almejada diante das metas programadas.

\footnotetext{
Como articulador, seu papel principal é oferecer condições para que os professores trabalhem coletivamente às propostas curriculares, em função de sua realidade, $o$ que não é fácil, mas possível; como formador, compete-lhe oferecer condições ao professor para que se aprofunde em sua área específica e trabalhe bem com ela; como transformador, cabe-lhe o compromisso com o questionamento, ou seja, ajudar o professor a ser reflexivo e crítico em sua prática. (ALMEIDA E PLACCO, 2011, Revista Educação).
}

A atuação da coordenação pedagógica além de técnica busca também promover uma ação política, critica e reflexiva, em que se busca valorar a humanização das pessoas envolvidas no campo educacional, atendendo as questões emocionais, sendo apoio de escuta, dialogando com alunos, família, professores e demais profissionais da educação. Assume uma postura de mediador dos conflitos existentes na escola.

Promover a articulação de todos os seguimentos escolares e até mesmo os não escolares é ação de uma coordenação compromissada com uma educação que tem seus princípios pautados na formação da cidadania, que valorize a formação holística do aluno dando a ele condições de uma aprendizagem de qualidade. Portanto ressalta-se que o coordenador não é o único profissional responsável por promover essa transformação. Mais 
cabe a ele ser articulador desse processo criando ações para a realização do trabalho participativo.

Portanto a presença do coordenador no espaço escolar torna-se essencial para que haja o fortalecimento de toda comunidade escolar. A ele será delegada a responsabilidade de solucionar conflitos, promover e organizar grupos de estudos e trocas de experiências entre os docentes, acompanhar o projeto político pedagógico, o planejamento, os projetos educacionais, promover a integração e participação da família no acompanhamento educativo dos alunos. O coordenador dará suporte ao professor para que esse consiga solucionar as dificuldades e desafios do dia a dia da sala de aula que acabam dificultando o processo formativo do aluno.

Portanto, a atuação da coordenação e do docente precisa manter-se em uma convivência agradável para que o trabalho flua de forma que os conflitos sejam sanados e ou amenizados no espaço escolar,

Cabe entre estes profissionais conseguir evitar o desconforto que atrapalha todo processo de aprendizagem e reconhecer às qualidades as fases positivas que ambas as profissões tem.

\section{METODOLOGIA DA PESQUISA}

Para realização desta pesquisa sobre a "coordenação pedagógica e suas atribuições para a prática docente na comunidade ribeirinha Mutuacá de Baixo, Cametá, no ano de 2019”. Apesar da diversidade teórica e metodológica com que é abordado o campo da pesquisa. Diante das varias reflexões sobre a Metodologia de Pesquisa conceituados pelos teoricos, argumenta-se que esta torna-se impresendivel para a realização de uma investiugação seria e comprometida com os preceitos metodologicos.

Para Gil (2017, p.01) “A pesquisa é desenvolvida mediante o concurso dos conhecimentos disponíveis e a utilização cuidadorasa de métodos e técnicas de investigação científica. $\mathrm{Na}$ realidade, a pesquisa desenvolve-se ao longo de um processo que envolve inúmeras fases, desde a adquada formulação dos problemas até a satisfatória apresentação dos resultados".

A importância da metodologia da pesquisa tem grande significancia para os estudos, conforme Sampieri, Collado e Lucio (2013, p. 548) “a meta da pesquisa mista não é substituir a pesquisa quantitativa nem a pesquisa qualitativa, mas utilizar os pontos fortes de ambos os tipos combinando-os e tentando minimizar seus pontos fracos". 
No decorrer desta pesquisa, o tipo de investigação abordada foi o método de natureza "Mista", por ter um amparo de conhecimento que se senta no campo quantitativo e qualitativo ambas têm técnicas para a coleta de dados, por isso, que o Método Misto tem objetivo de encontra o resultado concerto. Mas o Método Misto não significa só na modalidade de metodologia em particular e sim diversas referências epistemológicas, onde cabe referindo a um conjunto de metodologias.

Pois, o Método Misto vem desenvolver conceito numa perspectiva de pesquisa trazendo definições bem claras, para esse campo de conhecimento que traz técnica e fenômeno de pesquisa. De acordo com o pensamento de Sampieri, Collado e Lucio (2013), deve-se entender a busca de soluções práticas e trabalháveis para realizar pesquisa, ou seja, ir em busca de coleta e análise de dados para poder ser utilizado "os critérios e os desenhos mais apropriados para uma formulação”. Sampieri, Collado e Lucio (2013. P. 598),

O desenho de investigação determina uma perspectiva de estudo que vai buscar técnica para obter uma resposta na pesquisa, também através de um auto descritivo que aborda a pesquisa exploratória no desenho. Assim define-se o Desenho Sequencial transformador DITRAS, este buscará envolver duas etapas de investigação para levantar e colocar dados em que caberá o pesquisador definir qual delas utilizará primeiro. Assim a pesquisa será direcionada pela etapa quantitativa confrontada posteriormente com a qualitativa ambas se complementaram para evidenciar melhor resultado da investigação.

Nas modalidades do enfoque misto, normalmente aplica-se um instrumento que contém elementos quantitativos e qualitativos, cabe numa "combinação entre o método quantitativo e o qualitativo pode ocorrer em vários níveis. Em algumas situações a mistura pode "ir tão longe" como incorporar ambos os enfoques em todo o processo de pesquisa". Sampieri 2013, p. 563.

A pesquisa em termo do alcance definiu-se pelo exploratório, em que vai ser usado a definição do problema com maior necessidade, no critérios e compreensão da pesquisa, necessita ser flexível para análise dos estudos principalmente, nos aspectos dos fenômenos.

Para chegar num objetivo, tem que passar por uma pesquisa para ter um alcance, onde vai buscar no exploratório os dois campos de conhecimentos, que se caracterizam na quantitativa e qualitativa são duas fases que trabalhar na coleta e análise de dados, resultado desta ação é o de tirar partido de fato o fenômeno.

O estudo exploratório define-se pela fase de levantamento das bibliografias, correlação das variáveis em lócus de investigação, assim como a exploração de cada categoria escolhida para fazer parte do estudo. Entretanto, no alcance estuda o campo exploratório e em seguida o 
descritivo dentro do desenho misto, são duas técnicas que se combinam muito bem na pesquisa, no caráter sistemático e no pensamento de procedimento que são flexíveis, onde tem o poder de acumular várias informações, com tanto detalhe por parte do participante de que forem pesquisados. $\mathrm{O}$ estudo descritivo visa detalhar cada variável visando compreender como estas se relacionam no âmbito educacional. Além de descrever a influencias desta na formação discente. Assim o alcance descritivo direciona esse estudo buscando alcançar o melhor resultado, com seriedade e rigor metodológico.

Conceitua-se como universo a mesma característica da população que irá se trabalhar para extrair a sua amostra, A população investigada terá que ter disponibilidade para se obtiver de fato e a resposta para solucionar o estudo. Portanto pode definir o universo como conjunto de todas as espécies que entram na mira da investigação. Segundo Sampieri, Collado e Lucio (2013)

Segundo Sampieri, Collado e Lucio (2013) a amostra é o subconjunto extraído ao acaso deste universo. Destaca-se por população ou universo em uma pesquisa de natureza teórico-empírica, um grupo de pessoas envolvidas, objetos que possui um conjunto de características comuns que definem. Enfim a totalidade de pessoas, objetos ou evento que deseja estudar e realizar sobre a qual se efetivarão generalizações.

De acordo critérios propostos nos objetivos deste estudo, o tipo de amostra a ser seguido é o não probabilístico, por ser a que adequada ao contexto da pesquisa.

Quadro 1 - Amostra

\begin{tabular}{|c|c|c|c|c|}
\hline Sujeitos & Professores & Coordenadores & Gestores & Alunos \\
\hline População & 15 & 01 & 01 & 268 \\
\hline Amostra & $15=100 \%$ & $01=100 \%$ & $01=100 \%$ & Alunos \\
\hline $\begin{array}{l}\text { Unidade de } \\
\text { análise }\end{array}$ & \multicolumn{3}{|c|}{ E.M.E.F. De Mutuacá de Baixo } & $\begin{array}{c}\text { somente } \\
\text { sujeitos } \\
\text { observáveis }\end{array}$ \\
\hline
\end{tabular}

O instrumento de coletas de dados ocorrerá a partir de registros, de observações sistemática e através das medições das variáveis através do questionário buscaram levantar sobre o contextos e acontecimento que rodeia está pesquisa. Além de ter um objeto de estudo de interesse para esta pesquisa. A finalidade do questionário tem sua importância de coleta de dados e obter respostas, das pessoas de quem foi enviado o questionário, também se apresenta enumerais de vantagem e desvantagem. Sampieri, Collado e Lucio (2013, p. 584) afirmam muitos dos dados coletados pelos instrumentos mais comuns podem ser codificados como números e também analisados como texto". Para obter uma resposta que chegam com maior facilidade a uma resposta, para tabulação dos dados que segue na análise. 
Através de um questionário onde será aplicado com as seguintes pessoas o gestor, a coordenação e os professores com perguntas de múltipla escolha, para uma possível respostas, na perspectiva de aplicar a coleta de dados da referida pesquisa. No desenho misto o procedimento de "instrumento de coleta dos dados: coletar dados qualitativos e identificar temas e categorias. Posteriormente, estas serão utilizadas como base para localizar instrumentos padronizados que contém conceitos ou variáveis paralelas às categorias qualitativas". (Sampieri, Collado e Lucio, 2013, p.589).

Os procedimentos e aplicação dos instrumentos partirão em primeiro momento de coletas de dados quantitativos, na unidade escolar aplicando-se questionários com perguntas fechadas delimitando assim alternativas de respostas, estas por sua vez serão aplicadas com público das seguintes categorias na seguinte ordem, categoria docente, categoria da coordenação e categoria gestora.

No plano de análise dos dados é importante ir em busca do resultado através da análise investigativa. $\mathrm{O}$ desenho DITRAS tem como objetivo principal colaborar com a perspectiva teórica do pesquisador e, em ambas as fases, ele deve considerar as opiniões e vozes de todos os participantes e os grupos que eles representam. " Sampieri, Collado e Lucio (2013, P.572)

\subsection{ANALISE E DISCURSÕES DOS RESULTADOS}

\section{2- A coordenação pedagógica promove autonomia para que os docentes tenham flexibilidade na:}

\begin{tabular}{|l|c|c|c|c|c|c|}
\hline \multirow{2}{*}{ Variáveis } & \multicolumn{2}{|c|}{ Gestão } & \multicolumn{2}{c|}{ Coordenação } & \multicolumn{2}{c|}{ Docente } \\
\cline { 2 - 7 } & Fn & F\% & Fn & F\% & Fn & F\% \\
\hline Elaboração das ações metodológicas & - & - & - & - & 04 & $27 \%$ \\
\hline No uso da didática & - & - & - & - & - & - \\
\hline Na avaliação & - & - & - & - & - & - \\
\hline Todas as opções citadas & 01 & $100 \%$ & 01 & $100 \%$ & 11 & $73 \%$ \\
\hline Total & 01 & $100 \%$ & 01 & $100 \%$ & 15 & $100 \%$ \\
\hline
\end{tabular}

Interpretação: Conforme se observa na tabela $\mathrm{n}^{\circ} 02$, que traz informações referente a se a coordenação pedagógica promove autonomia para que os docentes tenham flexibilidade, observa-se que na categoria gestão $100 \%$ dos entrevistados todas as opções citadas. Já na categoria da coordenação $100 \%$ responderam todas as opções citadas, ou seja, elaboração das ações metodológicas, no uso da didática, na avaliação. E na categoria docente $73 \%$ responderam todas as opções citadas e $27 \%$ responderam elaboração das ações metodológicas.

\section{3- A coordenação pedagógica participa na tomada de decisão no espaço escolar?}

\begin{tabular}{|l|l|l|l|} 
Variáveis & Gestão & Coordenação & Docente \\
\hline
\end{tabular}




\begin{tabular}{|l|c|c|c|c|c|c|}
\hline & Fn & F\% & Fn & F\% & Fn & F\% \\
\hline Sim & 01 & $100 \%$ & 01 & $100 \%$ & 14 & $93 \%$ \\
\hline Não & - & - & - & - & - & - \\
\hline As vezes & - & - & - & - & 01 & $07 \%$ \\
\hline Raramente & - & - & - & - & - & - \\
\hline Total & 01 & $100 \%$ & 01 & $100 \%$ & 15 & $100 \%$ \\
\hline
\end{tabular}

Interpretação: Conforme se observa na tabela $n^{\circ} 03$, que traz informações referente a se a coordenação pedagógica participa na tomada de decisão no espaço escolar, observa-se que na categoria gestão $100 \%$ dos entrevistados responderam sim. Já na categoria da coordenação $100 \%$ responderam sim. E na categoria docente $93 \%$ sim e $07 \%$ responderam as vezes.

\section{4- A coordenação atua de modo democrático na escola.}

\begin{tabular}{|l|c|c|c|c|c|c|}
\hline \multirow{2}{*}{ Variáveis } & \multicolumn{2}{|c|}{ Gestão } & \multicolumn{2}{c|}{ Coordenação } & \multicolumn{2}{c|}{ Docente } \\
\cline { 2 - 8 } & Fn & F\% & Fn & F\% & Fn & F\% \\
\hline Sim & 01 & $100 \%$ & 01 & $100 \%$ & 13 & $87 \%$ \\
\hline Não & - & - & - & - & - & - \\
\hline As vezes & - & - & - & - & - & - \\
\hline Raramente & - & - & - & - & 02 & $13 \%$ \\
\hline Total & 01 & $100 \%$ & 01 & $100 \%$ & 15 & $100 \%$ \\
\hline
\end{tabular}

Interpretação: Conforme se observa na tabela $\mathrm{n}^{\circ}$ 04, que traz informações referente a se a coordenação atua de modo democrático na escola, observa-se que na categoria gestão $100 \%$ dos entrevistados responderam sim. Já na categoria da coordenação 100\% responderam sim. E na categoria docente $87 \%$ responderam sim e $13 \%$ responderam raramente.

\section{5- A coordenação trabalha de forma dialógica e flexível com o corpo docente}

\begin{tabular}{|l|c|c|c|c|c|c|}
\hline \multirow{2}{*}{ Variáveis } & \multicolumn{2}{|c|}{ Gestão } & \multicolumn{2}{c|}{ Coordenação } & \multicolumn{2}{c|}{ Docente } \\
\cline { 2 - 8 } & Fn & F\% & Fn & F\% & Fn & F\% \\
\hline Sim & 01 & $100 \%$ & 01 & $100 \%$ & 11 & $73 \%$ \\
\hline Não & - & - & - & - & - & - \\
\hline As vezes & - & - & - & - & 04 & $27 \%$ \\
\hline Raramente & - & - & - & - & - & - \\
\hline Total & 01 & $100 \%$ & 01 & $100 \%$ & 15 & $100 \%$ \\
\hline
\end{tabular}

Interpretação: Conforme se observa na tabela $n^{\circ} 05$, que traz informações referente a se a coordenação trabalha de forma dialógica e flexível com o corpo docente, observa-se que na categoria gestão $100 \%$ dos entrevistados responderam sim. Já na categoria da coordenação $100 \%$ responderam sim. E na categoria docente $73 \%$ responderam sim e $27 \%$ responderam as vezes.

\section{6- Que papel tem a coordenação no ambiente escolar?}

\begin{tabular}{|l|c|c|c|c|c|c|}
\hline \multirow{2}{*}{ Variáveis } & \multicolumn{2}{|c|}{ Gestão } & \multicolumn{2}{|c|}{ Coordenação } & \multicolumn{2}{c|}{ Docente } \\
\cline { 2 - 6 } & Fn & F\% & Fn & F\% & Fn & F\% \\
\hline
\end{tabular}




\begin{tabular}{|l|c|c|c|c|c|c|}
\hline Papel meramente informativo & - & - & - & - & 01 & $07 \%$ \\
\hline Papel transformador e formador & - & - & - & - & 08 & $53 \%$ \\
\hline Papel instrutivo & - & - & - & - & - & - \\
\hline Promovedor da cidadania & - & - & - & - & - & - \\
\hline Todas as opções & 01 & $100 \%$ & 01 & $100 \%$ & 06 & $40 \%$ \\
\hline Total & 02 & $100 \%$ & 01 & $100 \%$ & 15 & $100 \%$ \\
\hline
\end{tabular}

Interpretação: Conforme se observa na tabela $n^{\circ} 06$, que traz informações referente a pergunta que papel tem a coordenação no ambiente escolar, observa-se que na categoria gestão $100 \%$ dos entrevistados responderam todas as opções. Já na categoria da coordenação $100 \%$ responderam todas as opções. E na categoria docente 53\% responderam papel transformador e formador, $40 \%$ responderam todas as opções e $07 \%$ responderam papel meramente informativo.

7- Quais dificuldades são apontadas no trabalho da coordenação escolar.

\begin{tabular}{|l|l|l|l|l|l|l|l|}
\hline \multirow{2}{*}{ Variáveis } & \multicolumn{2}{|l|}{ Coordenação } & \multicolumn{2}{l|}{ Gestão } & \multicolumn{2}{l|}{ Docente } \\
\cline { 2 - 8 } & Fn & F\% & Fn & F\% & Fn & F\% \\
\hline No desenvolvimento do trabalho participativo & - & - & 01 & $100 \%$ & 02 & $13 \%$ \\
\hline Nas ações pedagógicas & - & - & - & - & 03 & $20 \%$ \\
\hline Nas ações administrativas & 01 & $100 \%$ & - & - & 10 & $67 \%$ \\
\hline Total & 01 & $100 \%$ & 01 & $100 \%$ & 15 & $100 \%$ \\
\hline
\end{tabular}

Interpretação: Conforme se observa na tabela $n^{\circ} 07$, que traz informações referente a se quais dificuldades são apontadas no trabalho da coordenação escolar, observa-se que na categoria gestão $100 \%$ dos entrevistados responderam nas ações administrativas. Já na categoria da coordenação $100 \%$ responderam no desenvolvimento do trabalho participativo. E na categoria docente $67 \%$ responderam nas ações administrativas, $20 \%$ responderam nas ações pedagógicas e $13 \%$ responderam no desenvolvimento do trabalho participativo.

\section{8- Como se efetiva o papel da coordenação no cotidiano escolar.}

\begin{tabular}{|l|c|c|c|c|c|c|}
\hline \multicolumn{1}{|c|}{ Variáveis } & \multicolumn{2}{c|}{ Gestão } & \multicolumn{2}{c|}{ Coordenação } & \multicolumn{2}{c|}{ Docente } \\
\cline { 2 - 7 } & Fn & F\% & Fn & F\% & Fn & F\% \\
\hline $\begin{array}{l}\text { Desempenhando um trabalho coletivo e participativo } \\
\text { assistindo o docente em suas dificuldades pedagógicas. }\end{array}$ & - & - & - & - & 02 & $13 \%$ \\
\hline Dando autonomia aos sujeitos escolares & - & - & - & - & 03 & $20 \%$ \\
\hline Promovendo projetos & - & - & - & - & 03 & $20 \%$ \\
\hline Partilhando responsabilidades nas ações escolares & - & - & - & - & 02 & $13 \%$ \\
\hline Averiguando e fiscalizando o trabalho do docente & - & - & - & - & - & - \\
\hline Todas as opções & 01 & $100 \%$ & 01 & $100 \%$ & 05 & $34 \%$ \\
\hline Total & 01 & $100 \%$ & 01 & $100 \%$ & 15 & $100 \%$ \\
\hline
\end{tabular}

Interpretação: Conforme se observa na tabela $n^{\circ} 08$, que traz informações referente a se como se efetiva o papel da coordenação no cotidiano escolar observa-se que na categoria gestão $100 \%$ dos entrevistados responderam todas as opções. Já na categoria da coordenação 
$100 \%$ responderam todas as opções. E na categoria docente $34 \%$ responderam todas as opções, 20\% responderam dando autonomia aos sujeitos escolares, 20\% responderam promovendo projetos, $13 \%$ responderam desempenhando um trabalho coletivo e participativo assistindo o docente em suas dificuldades pedagógicas e $13 \%$ responderam partilhando responsabilidades nas ações escolares.

\section{ANALISE CONCLUSIVA}

Evidenciou-se que a coordenação pedagógica promove autonomia para que os docentes tenham flexibilidade, ao observar que nas categorias da gestão e da coordenação e docentes ambas em sua maioria dos entrevistados optaram por todas as opções citadas, ou seja, elaboração das ações metodológicas, no uso da didática, na avaliação.

\footnotetext{
"Saber que devo respeito à autonomia, à dignidade e à identidade do educando e, na prática, procurar a coerência com este saber, me leva inapelavelmente à criação de algumas virtudes ou qualidades sem as quais aquele saber vira inautêntico, palavreado vazio e inoperante. " FREIRE, (1996, P. 62).
}

Para o autor, conceituar esta ideia de autonomia, na prática da educação tem que envolver todo o corpo docente da escola, para poder levanta as virtudes da escola, para promover os passos necessários para uma educação de qualidade. Já que a escola demostra, este passo inicial promovendo ações e flexão entre a comunidade escolar, buscando envolver a todos nas metodologias que a escola desenvolve através da autonomia na prática educativa. A autonomia na pratica do coordenador, do gestor e do professor é um elemento fundamental para que as atividades escolares tenham efeito positivo.

Sobre as informações referentes se a coordenação pedagógica participa na tomada de decisão no espaço escolar, notar que na categoria gestão e coordenação dos entrevistados responderam $100 \%$ sim. Já na categoria docente 93\%. Portanto a participação de todos é fundamental para que a educação tenha efeito positivo.

No que concerne se a coordenação atua de modo democrático na escola, observar que ambas categorias de gestão e da coordenação 100\% responderam sim. E na categoria docente $87 \%$ responderam sim. Demostra que a maioria da categoria docente também ver a coordenação de forma democrática dentro do espaço escolar.

Sobre a coordenação trabalha de forma dialógica e flexível com o corpo docente, evidenciou-se que na categoria gestão e coordenação $100 \%$ responderam sim, apontam um aspecto bem positivo para o corpo docente da escola. Visto que, na categoria docente $73 \%$ responderam sim e $27 \%$ responderam as vezes, esse resultado também traz um ponto positivo, 
que os docentes de $73 \%$ demostra que a coordenação está dando, também um pouco de assessoria no seu trabalho.

Sobre o papel da coordenação no ambiente escolar, observar que ambas categorias gestão e coordenação $100 \%$ responderam todas as opções. E na categoria docente $53 \%$ responderam papel transformador e formador, $40 \%$ responderam todas as opções. A categoria docente com maioria de 53\% vê o papel coordenador como transformador e formador da educação. Conforme diz Placco (2004),

\footnotetext{
"o principal objetivo do coordenador pedagógico é a formação continuada, momento único e imprescindível onde o coletivo da escola se reúne para estudar e aprimorar o estudo em grupo e o conhecimento. É um instante especial para o processo escolar, e o coordenador pedagógico tem a função de planejar, preparar, administrar este momento de estudo. Essa formação continuada dinamiza as ações da escola, proporcionando um meio transformador e que promove a interação entre toda a comunidade escolar." (Placco, 2004. p. 45),
}

Para Domingues (2014) é função do coordenador pedagógico, ser o articulador da formação continuada dos professores na escola. A autora considera a atividade de formação continuada, desenvolvida pelo coordenador, como sendo um saber-fazer multideterminado, decorrente da formação pessoal, da organização institucional e das políticas públicas. Por isso, tem sempre um objetivo para alcançar, vislumbrar um novo caminho que possa atender aos interesses dos educadores e da própria sociedade necessita.

Demostrando um proporcionalmente positivo de uma coletividade efetiva cotidiana escolar, no trabalho do papel do coordenador da escola pesquisada. Para Adriano, (2017, p.109) o coordenador precisa considerar o contexto de totalidade, coletividade e complexidade da equipe pedagógica para conseguir desenvolver um trabalho promissor.

Isso significa que ambas as categorias o pitaram positivamente para apresentar o papel que é desempenhado no espaço escolar de forma flexível e participativo.

Franco (2008, p. 128) essa tarefa de coordenar o pedagógico não é uma tarefa fácil. É muito complexa porque envolve clareza de posicionamentos políticos, pedagógicos, pessoais e administrativos. Como toda ação pedagógica, esta é uma ação política, ética e comprometida, que somente pode frutificar em um ambiente coletivamente engajado com os pressupostos pedagógicos assumidos.

Com posso observar que entre a categoria da gestão e docente afirma todas as opções propostos nos campos de conhecimento apontado, como participação dos pais, o trabalho coletivo, a autonomia do professor e a coordenação participativa. Afirma a falta de interesse 
do próprio aluno, leva a escola apresentar que o fracasso escolar não vem dos trabalhos escolares, pedagógicos, gestores, mas sim do próprio aluno.

Segundo Adriano (2017, p. 107) “infere ações que abrangem várias questões relacionadas aos trabalhos desenvolvidos na escola, juntamente com as interações que dispõem aos diversos atores educacionais. "

\section{REFERÊNCIAS}

ADRIANO, Graciele Alice Carvalho. Gestão Educacional: UNIASSELVI, 2017.

DOMINGUES, I. (2014). O coordenador pedagógico e a formação contínua do docente na escola. São Paulo, SP: Cortez.

FREIRE, Paulo. Educação e mudança. Rio de Janeiro: Paz e terra, 1996.

FRANCO, F. C. Gestão e coordenação do trabalho pedagógico na educação básica. Mogi das Cruzes: EAD/UBC, 2008.

FRANCO, F. C. As reuniões na escola e a construção coletiva do projeto educacional. São Paulo: Loyola, 2010. FREIRE, P. Extensão ou comunicação? Rio de Janeiro: Paz e Terra, 1996.

GIL, Antônio Carlos. Como elaborar projetos de pesquisa. - 6. ed. - São Paulo: Atlas, 2017.

GROCHOSKA, Marcia Andreia. Organização escolar: perspectivas e enfoques. 2.ed. ver.- Curitiba: Inter Saberes, 2014.

HERNÁNDEZ SAMPIERI, Roberto. Metodologia de pesquisa. Carlos Fernández Collado, María del Pilar Baptista Lucio; tradução: Daisy Vaz de Moraes; revisão técnica; Ana Gracinda Queluz Garcia, Dirceu da Silva, Marcos Júlio. 5.ed.- Porto Alegre: Penso, 2013.

PLACCO, V.M.N. DE S. E ALMEIDA, L.R. (org.). O coordenador pedagógico e o cotidiano da escola. São Paulo: Edições Loyola, 2011.

PIMENTA, S. G. Formação de professores-saberes da docência e identidade do professor. Nuances: Estudos sobre Educação, v. 3, n. 3, 1997. 